\title{
The Performance of Health Workers in Ethiopia Results from Qualitative Research
}

\author{
Magnus Lindelow \\ The World Bank \\ mlindelow@worldbank.org \\ Pieter Serneels \\ Centre for the Study of African Economies, University of Oxford \\ Teigist Lemma \\ International Labour Organization, Addis Ababa
}

\begin{abstract}
World Bank Policy Research Working Paper 3558, April 2005
The Policy Research Working Paper Series disseminates the findings of work in progress to encourage the exchange of ideas about development issues. An objective of the series is to get the findings out quickly, even if the presentations are less than fully polished. The papers carry the names of the authors and should be cited accordingly. The findings, interpretations, and conclusions expressed in this paper are entirely those of the authors. They do not necessarily represent the view of the World Bank, its Executive Directors, or the countries they represent. Policy Research Working Papers are available online at http://econ.worldbank.org.
\end{abstract}




\begin{abstract}
Insufficient attention has been paid to understanding what determines the performance of health workers and how they make labor market choices. This paper reports on findings from focus group discussions with both health workers and users of health services in Ethiopia, a country with some of the poorest health outcomes in the world. We describe performance problems identified by both health users and health workers participating in the focus group discussions, including absenteeism and shirking, pilfering drugs and materials, informal health care provision and illicit charging, and corruption. In the second part of the paper we present four structural reasons why these problems arise: (i) the ongoing transition from a health sector dominated by the public sector, toward a more mixed model; (ii) the failure of government policies to keep pace with the transition toward a mixed model of service delivery; (iii) weak accountability mechanisms and the erosion of profe ssional norms in the health sector; and (iv) the impact of HIV/AIDS. The discussions underline the need to base policies on a micro-analysis of how health workers make constrained choices, both in their career and in their day to day professional activities .
\end{abstract}

Key words: health worker performance, human resources for health, corruption

JEL Code: J44, E19 
"May I always act so as to preserve the finest traditions of my calling"

Hypocratic Oath - modern version

\section{INTRODUCTION}

It has long been recognized that human resources are an essential input into the delivery of health services. The human resource policy agenda has gradually shifted from a focus on workforce expansion and manpower planning, to concern with quality and financial sustainability (Martinez \& Martineau, 1998). Yet, in many countries, human resource policy continues to be premised on the notion that health workers are passive actors that are both competent and motivated to serve the public. Recently, the limitations of this approach have become apparent. Health systems are today dealing with difficult reforms and transitions: expansion of the private sector, public sector and civil service reforms, growth in international migration, HIV/AIDS, etc. These challenges have had a dramatic impact on the opportunities and motivation of health professionals. Rather than being passive actors, they have responded purposively and strategically to these changing circumstances.

There is now broad agreement that the inadequate attention to human resource issues in the health sector has contributed to serious problems in many health systems, including internal and external brain drain, unequal geographical distribution of health workers, low morale, informal charging, etc. (Dussault \& Dubois, 2003; ILO, 1998; Joint Learning Initiative, 2004; PAHO, 2001; USAID, 2003; Van Lerberghe, Adams, \& Ferrinho, 2002; WHO, 2002). National governments, development agencies, and the academic community have come up with a range of proposals for addressing these challenges: increasing and decompressing salaries; improving recruitment; implementing performance monitoring and reward systems; upgrading training quality; and developing and implementing practice standards. Although many of these proposals may have merit, their empirical found ations are often weak-i.e. the policy proposals are often not rooted in a solid understanding of how health workers make choices in the labor market, or of the nature and source of performance problems.

This paper comprises an effort to fill this gap. It focuses on health workers in Ethiopia, a country with some of the worst health indicators in the world. ${ }^{1}$ Although both the network of facilities and the health workforce have been expanded dramatically in recent years, the number of health workers relative to population remains low, with a concentration in urban areas. ${ }^{2}$ The situation of health workers in the country also has changed drastically in recent

\footnotetext{
${ }^{1}$ Respiratory infection, diarrhea, malnutrition, and malaria contribute to high levels of infant and child mortality (estimated at 113 and 171 respectively for 2002, below regional averages for Sub-Saharan Africa) (UNICEF, 2003). Limited access to and quality of family planning and maternity care also contribute to high levels of maternal mortality. For a detailed discussin of health outcomes and the Ethiopian health system more broadly, see World Bank (World Bank \& Ministry of Health (Ethiopia), 2004).

${ }^{2}$ Between 1997 and 2002, the number of health officers and nurses increased from 30 to 484 and 4,774 to 12,838 respectively. Ethiopia still has one of the lowest health worker per population ratios.
} 
years. The delivery of health services in Ethiopia was long dominated by the public sector. ${ }^{3}$ However, after being banned for many years, the private sector was legalized in the mid1990s, and the number of private for-profit facilities, pharmaceutical retail outlets, and NGO and faith-based providers has expanded steadily. The government has now made the expansion of the private health care sector an explicit policy objective, but the institutional framework remains weak. Health workers are also on the frontlines in the ongoing battle against the HIV/AIDS crisis.

How do these changes affect the behavior of health workers - on the job and in the labor market? To addresses these question we follow a bottom up approach. The paper reports the findings from nine focus group discussions; six with health workers and three with users of health services. They were implemented in March 2003 in both the capital, Addis Ababa, and a provincial town. In each of the two locations, separate discussions were held with medical doctors and health officers, nurses and midwifes, health assistants, and users of health services. ${ }^{4}$ The participants were selected to promote heterogeneity in terms of sex, sector of employment, and family circumstance. At the same time, the separation of different occupational groups ensured sufficient status-homogeneity to permit open exchange of ideas within each group. Due to the considerable heterogeneity of users in Addis Ababa, separate discussions were held with relatively well-off individuals who primarily use private clinics, and with relatively poor users who mostly visit public facilities. ${ }^{5}$

The paper seeks to make two contributions. First, the detailed and contextual information provided by the focus group discussions helps to better understand the nature of health worker performance and human resource problems in the health sector in Ethiopia. This understanding is an important building block for improved policy-making. Second, the qualitative research is useful for generating hypotheses that can be tested with further (quantitative) research. The paper is organized as follows. In section 2, we describe the challenges as identified by users and health workers themselves, while in section 3 , we discuss the reasons why these problems have arisen. Section 4 concludes.

\footnotetext{
${ }^{3}$ Seventy-one percent of hospitals, 94 percent of health centers, 82 percent of health stations and all health posts are currently run by the Government. In contrast, the pharmaceutical sector is dominated by the private sector, with more than 80 percent of pharmacies, drug shops, and rural drug vendors in private ownership.

${ }^{4}$ Health officers have the same function and status as doctors and represent a significant part of the labor force in the health sector in Ethiopia. The nurses and midwifes have at least two years of formal training after secondary school. Health assistants typically have one year of formal technical training.

${ }^{5}$ A detailed account of the composition and organization of the discussions, and the analysis of the data is provided in the appendix.
} 


\section{Health Worker Performance And Labor Market ChOICES : The Challenges}

A growing literature is documenting problems with health service delivery, including absenteeism of health workers (Chaudhury, Hammer, Kremer, Muralidharan, \& Rogers, 2004; Ensor \& Witter, 2001; Ferrinho, Van Lerberghe, Julien, Fresta, Gomes, Dias et al., 1998), informal charging (Belli, Gotsadze, \& Shahriari, 2004; Ensor, 2004), pilfering of drugs and materials (McPake, Asiimwe, Mwesigye, Ofumbi, Orthenblad, Streefland et al., 1999) and low levels of motivation (Franco, Bennett, \& Kanfer, 2002). Many of the performance problems can be understood as coping mechanisms by health workers operating in an adverse environment (Ferrinho, Omar, Fernandes, Blaise, Bugalho, \& Lerberghe, 2004; Ferrinho \& Van Lerberghe, 2002). To what extent are these problems present in Ethiopia, and how are they perceived by the different actors? Both health workers and users provide a sobering account that indicates a high level of distrust and frustration with the public health system. ${ }^{6}$

Before, I was frequently visiting the public facility, until I became a diabetic patient. Health workers do not respond to patients' needs unless we are on a stretcher. On one of my last visits, I waited in a long queue before entering the examination room. The health worker saw me and commented impolitely that she would attend ten patients only and that I did not look like a diabetic patient. Finally she asked me to leave the examination room. This was the last time I visited a public health provider. I am now visiting a private facility, which I cannot really afford.

User in a provincial town

I used to visit public facilities until I had a bad experience. Some years ago, my wife was in labor, we went to a public facility and she was left unattended for three days. She was then referred to an NGO clinic and the health workers informed me that if she had been left unattended for another thirty minutes, both mother and child would have died. This experience helped me decide to never return to a public facility. Now I consider it as a place of demise, not of diagnosis and treatment. I do not have the capacity to pay for private care but if serious health problems arise in the family, I would go to a private clinic. And if I do not have the money, I will just stay at home resting in mybed.

User in a provincial town

Patients need to be approached in a psychological way-they need to be well received. They need a polite dialogue more than medicine, but this is not available in public facilities.

User in a provincial town

The discussions reveal that these frustrations are rooted in a number of more specific complaints. At the most basic level, many participants point out that health workers in public

\footnotetext{
${ }^{6}$ The quotes reported in the paper are selected both on basis of salience, and because they reflect a common theme in the discussions. Full transcripts are available from the authors upon request. We emphasize that the group discussions focus on human resource problems. Hence, we do not adequately capture the many positive experiences that both health workers and users have. This approach was chosen as the most direct method to understanding current issues and identifying potential solutions. It should not be seen as an attempt to denigrate the significant achievements of the Ethiopian health sector, or its professionals.
} 
facilities are often absent during working hours, or that they are simply "sitting around" while patients are waiting.

Usually patients have to wait long for physicians. And after examining 3 or 4 people, health workers say that it is tea break and patients have to wait until the staff return. This usually takes long. There is a lot of suffering during this time.

User in Addis Ababa

The problem of absenteeism is acknowledged by health workers themselves.

We observe it -we cannot lie about it. Not respecting working hours is something we got used to and this has created a problem for the patients. During tea time, for example, people go to other places-to work in the private sector, for personal commitments, etc. Even the small amount of time we have in the facility we do not use effectively.

Health assistant in a provincial town

The comments point at the links between the public and private sector activities. While private health care undoubtedly can make a positive contribution, its expansion can also have negative effects, especially in a poorly regulated environment, where the line between the public and private sector is blurred. Users complain, for example, of opportunistic referrals to the private sector by health workers in the public sector.

I once had pain in my ear and visited a public provider. I was told by a health worker to go to a different clinic in the afternoon. The reason - I was told — was that the machine for examining my ear was old. When I went to the private clinic I was referred to, I found the same health worker and he examined me with a better machine and charged much more.

User in a provincial town

Even for purchasing the prescribed drugs, we are referred to particular pharmacies. It seems that the physician who is prescribing is selling his own medicine in a particular pharmacy.

User in a provincial town

Both health workers and users also point out that there is an active informal health care market, including curative care provided in the home of health workers or pharmacies, as well as home-care for the chronically ill or patients who have undergone surgery.

There are instances where medical advice, prescriptions, injections, and laboratory tests are given from home. For example, in one of the nearby towns, [names town], some years back, there were places where you could knock on the door, they let you in to the living room, and after a few minutes waiting you get all the service you need, including laboratory investigation.

Health assistant in a provincial town

Services are provided at home, but this is very expensive. Nurses give injections at home. Most of the time, $i$ is the patient who has to buy the medicines and they provide injections and change the dressing. In some cases they also prescribe medicines. So it is possible to get nurses and they do provide a good service. They are approached very informally.

User in Addis Ababa 
There are pharmacies that serve as clinics. In many places there are nurses who work in the pharmacies although this is not legal. In rural areas these people usually have a drug vendor shop but inside it is a clinic.

Nurse/midwife in Addis Ababa

The large private and informal health care market has also created a new source of demand for drugs and other medical supplies. It seems that, at least in part, this demand is met from public facilities. Indeed, the focus group participants acknowledge that pilfering of drugs and other supplies is a problem, and that it sometimes takes an organized form.

I have worked in a private pharmacy. There are drugs that come in illegally and we know their source-there are people who are caught red-handed. The black market involves a large quantity and variety of drugs. This is an obvious complaint-it is real. Drugs are taken from public facilities.

Health assistant in a provincial town

Drugs are available in private but not public facilities. There is a hidden business going on, where the main actors are health workers.

User in a provincial town

Users also complain about other barriers to accessing public facilities, such as unofficial charges for basic materials like syringes, gloves, and IV fluid, or side payments for basic conveniences in the clinic. They also point out that individual relationships are important for getting appointments, skipping queues, accessing drugs and receiving a polite and appropriate treatment.

Some people have to pay bribes in the public facility even to get registered.

User in a provincial town

Even for changing bed sheets one has to bribe cleaners with a few Birr. The same holds for food for patients in the wards.

User in Addis Ababa

Even if there is a bed, they give priority to those who come through relationships and not to those who are on the verge of death. I have good social relationships with people because of my social status. But if this had happened to a poor person, it would all end up for the worst.

User in Addis Ababa

Health workers acknowledge that complaints about poor treatment or inadequate service are common, and in many cases justified. But the real causes are seen as beyond the control of health professionals, and having to do with excessive workload, inadequate facilities and a lack of material. This is a source of frustration for many health workers and affects their motivation, which in turn affects their performance. Many feel that a career in the health sector has become less attractive.

I would not advise a person to join the health sector. I want to leave this sector because of the workload and the low payment. I would advise a person to study for another profession. 
Overall, both health workers and users paint a bleak picture of the public sector, and many users remark that they would only consider visiting the public sector as a last resort.

Although I do not have the economic capacity, I use a private provider because I feel responsible to take care of my health. There is no health service in the public facilities and so we have to go elsewhere.

User in a provincial town

Not surprisingly, it is the poor who are bearing most of the cost of the failing public sector.

We thought that quality of service would have been maintained by the opening up of the private sector because the burden on the public sector would be reduced and the poor would benefit from the public services. Now the poor are suffering most. They are still exposed to the same problems and die without accessing the health service; some pass away while waiting on a stretcher.

User in Addis Ababa

\section{Explaining The Performance AND Labor Market CHOICES Of Health WORKERS}

Both health workers and users express frustration with the current situation. But what explains the performance problems described above and why is the morale of health workers so low? The group discussions point to four structural reasons. First, the Ethiopian health sector is undergoing a transition-from being dominated by the public sector, towards a more mixed model. This transition creates both opportunities and uncertainties, and many health workers are struggling to find their way in the new environment. Second, the government regulation has not kept pace with the ongoing transition towards a mixed model of service delivery. As a result, procedures and practices are outdated and poorly enforced, while also being prone to favoritism. Third, both professionalism and integrity have been steadily undermined. Petty corruption, absenteeism, and other forms of inappropriate behavior now seem commonplace, and are increasingly seen as accepted features of the system. Finally, the HIV/AIDS crisis has had a big impact on health worker motivation and behavior.

\subsection{A health sector in transition}

Although the private health sector is young and relatively small in Ethiopia, its emergence and growth has already had a big impact on the public sector. Health workers themselves draw a sharp distinction between the two sectors. The public sector is associated with bw compensation, a lack of promotion and career development opportunities, and shortages of essential equipment and material. In contrast, compensation is the main appeal of 
the private sector; the most educated professional categories can earn several times more in the private sector.

No physician would leave the public sector if he or she was paid well. The reason for the attrition is purely financial - the salary in the public sector is like a tip. The average salary for a physician in the government is 980 Birr [118 USD] of which 300 Birr [36 USD] is for tax. By moving to the private sector we can earn three or four times as much. The payment to physicians needs to be improved if there is a genuine drive to help the poor.

Physician/health officer in a provincial town

But financial rewards are not the only issue. Health workers point out that better infrastructure, equipment, and material in the private sector provide for better opportunities to apply and develop their professional skills.

There is inadequate supply of material [in the public sector]. It is not possible to work efficiently and meet expectations. If you try to work with what is available, your service will be sub-standard, and eventually you might be forced to drop your ethics.

Health assistant in a provincial town

In response many health workers have pursued opportunities in both the for-profit and not-for-profit private sectors. Despite legal constraints on public sector workers seeking fulltime employment in the private sector, both new and experienced public sector workers are seeking employment in the private sector. Many hold part-time private jobs, while keeping their position in the public sector. In urban areas it is easy to find private employment in evenings and on weekends. In principle, one should get permission, but it is not considered essential.

But while the private sector is seen as having clear advantages, it also has drawbacks. Health workers remark that most private clinics are owned by lay investors, whose primary motive is profit. $^{7}$ The profit motive has positive consequences for performance, but health workers complain of heavy workloads, limited training opportunities, and a lack of jobsecurity.

I served 5 years in the private sector and have not attended any form of training. If it were not for the higher earnings, I would not stay in the private sector.

Physician/health officer in a provincial town

Many of the health workers with experience from the private sector also report feeling under pressure to engage in unethical practices, in particular provision of unnecessary services.

I am not happy with the private sector. Some [managers/owners] force us to over-prescribe investigations for patients. As a professional, I should prescribe only the necessary investigations, but owners are interested in more to generate income.

Physician/health officer in a provincial town

\footnotetext{
${ }^{7}$ Most health workers face a financial constraint and cannot find the required funding to set up a pharmacy or a clinic which require a start capital of 1,000-2,500 USD and 6,000-8,000 USD respectively.
} 
I opened a private clinic. When you are a professional and act ethically, it is difficult to survive the competition. Insisting on appropriate investigation reduces the amount of income-I am an example of someone who failed and was forced to leave the market. The fees I charged were the same as those charged by other private providers, but unless one works like a merchant by over-prescribing and over-diagnosing, it is difficult to survive.

Physician/health officer in a provincial town

These experiences are now increasingly dissuading health workers from leaving the public sector. At the same time there is a growing awareness in the Ministry of Health that to retain workers public sector careers must be made more attractive, and it has started to develop new salary scales and more transparent career structures (Ministry of Health, 1999). Some regions have also expanded allowances and bonuses. As a result, salary differentials are narrowing, and the "internal brain drain" to the private sector has declined. Some health workers speak of a reverse flow of health workers back to the public sector.

I tried to work 2 years in a private clinic and came back to the public sector. When I resigned from the public sector, many others were also leaving the public facilities because of the low payment we received. Now the salary in the public sector has increased to 670 Birr [80USD] per month. In the private sector it is about 600 Birr [72USD]. This, in addition to the education opportunities that have opened up in the public facilities, helped me decide to come back to the public sector. Now we can join training courses to become senior nurses. It seems that the public sector is getting better.

Health assistant in a provincial town

Even with these changes, many health workers still see distinct qualities in each sector; the public sector offers job security, benefits, and access to training, while a private sector job offers flexibility, higher payment, and access to modern technology. Because of this complementarity, many health workers aspire to combining public and private sector jobs. It illustrates how private sector growth has given them more control over their careers.

\subsection{Weak human resource policies}

While the private health sector has been expanding, and the tensions between the public and private sectors grown more apparent, human resource policies have lagged behind. They suffer from two fundamental problems. First, the policies are still rooted in a commandand-control approach that leaves little room for a health worker's individual preferences. Second, policies are poorly enforced and are prone to favoritism.

A good example of the first is the lack of regulation concerning the combining of public and private sector work. Another illustration, and how this may have wide spread consequences is provided by the job allocation system. The majority of medical and nursing students are funded by either the federal or regional government. ${ }^{8}$ In exchange for free

\footnotetext{
${ }^{8}$ Most training schools and universities are financed by the (federal or regional) government and education is virtually free. Aside from three established not-for-profit schools, private schools are a
} 
training, health workers are required to serve a fixed number of years in a public facility. Only after this period can they get "release" from the public sector. The allocation of health workers to their first public sector job is organized as a lottery, where the Ministry of Health randomly draws a post for each student. If the education was funded by the regional government, the health worker will be deployed to a facility in that region. In theory, the lottery outcome is the final say, and postings can only be refused for health reasons or familyrelated considerations. However, it appears that these arrangements no longer work in the presence of a thriving private sector. Health workers find ways to leave their allocated posting before having completed the assignment, or to start to work in the private sector without a release.

Current policies do not take into account that health workers have individual preferences and outside options. As a consequence the allocation system fails in one of its important functions: the distribution of health workers to rural and urban areas. Most health workers perceive few upsides to a rural posting, especially not in the long run, but they are well aware of the need for rural health care and express a readiness to accept a rural posting as a contractual obligation for a limited period. However, the government does not provide compensation for the sacrifices associated with rural postings - either in the form of location bonuses or promises of future training opportunities. These outdated policies are undermining the willingness of young health workers to take up a rural posting.

I was assigned to a very remote area some $38 \mathrm{~km}$ from the local town and $18 \mathrm{~km}$ off the main road but I did not go. Two years later, there was a new graduate who was sent there. He served for 1 month and could not collect his salary unless he traveled $18 \mathrm{~km}$ by horse. After 2 months he packed his belongings, managed to collect his salary, and then left straight for Washington DC.

Physician/health officer in a provincial town

recent phenomenon, their student numbers are still small, and a certification procedures is still to be established. 
Once you are dumped in the most remote area, no one will remember your transfer back to a central area. In addition, there are no medicines, books and you cannot access information and opportunities needed to improve your professional standards. My colleague, Tesfaye, and I left the public sector due to lack of refreshment courses, transfer and education. Had these needs been fulfilled, we would not have left the public sector. Such problems can be resolved by policy makers

\section{Physician/health officer in a provincial town}

The failure of human resource policy to face up to the reality of the private sector comes at a cost in terms of the availability and quality of services in the public sector. The Ministry of Health is aware of the need for new regulations and some new policy initiatives are encouraging. With respect to combining public and private sector work one example is the current debate on 'special pharmacies' or private pharmacies in public health facilities (Walelign \& Yusuf, 2002), another is the discussion on private wings in public hospitals (Ministry of Health, 2003). On the issue of rural posting, the most dynamic regions are recognizing the problem and have started offering surplus payment for remote postings. However, these innovations are taking time to be implemented.

While formal policy responses have been slow, informal arrangements have been more quick to adapt. They take many forms, ranging from favoritism to explicit corrupt practices. For example, although a graduating student cannot normally refuse a posting assigned through the lottery, it seems that individuals with the right connections are able to turn down their initial assignment and wait for a better one. There are also cases where students are allowed to swap their postings - sometimes with an accompanying financial transfer. The general view among health workers is that the lottery system is corrupt and that assignments are not truly random.

We were sent to the regions after the lottery at the Ministry of Health in Addis Ababa. If one has blood or ethnic affiliation with the region one is assigned to, it is possible to get a more central place. You are privileged if you are from the same ethnic group. This is how it has worked for the last 10 years.

Physician/health officer in a provincial town

The Ministry of Health makes promises about transfers [away from rural facilities], but they usually only happen when new graduates arrive. And even this works only for people from the same ethnic group. In all other cases, you will be forgotten and stuck in your initial assignment.

Physician/health officer in a provincial town

Existing policies are often perceived as unfair and lacking in transparency. Health workers complain about wide spread favoritism in transferring professionals from remote to urban areas, with those who do mt have the right connections to fearing 'getting stuck' in a remote area. 
Workers who have relatives in the right places stay in urban areas and the rest go to the rural and remote areas. Those who do not have relations, kinship or friends will never come back unless they have reliable contacts at management and higher levels.

Nurse/midwife in a provincial town

Similar complaints of favoritism are expressed with respect to access to training, promotion, and gaining release from the public sector. ${ }^{9}$ This perceived unfairness has eroded the confidence of health workers in government policies and is a source of permanent frustration. It has contributed to a growing cynicism and "fend-for-yourself" attitude, with implications for how health workers make choices in the labor market.

Health workers insist that a serious reform of human resource policies is needed-one that adapts the policies to the current reality and that addresses favoritism and corruption. A potential opportunity in this respect is the decentralization of public health to the Wereda (district) level. Increased local competition among Weredas may improve conditions - e.g. by increasing the salary levels for remote areas. At the same time, without equalizing measures, decentralization can worsen the situation in poor Weredas.

\subsection{The acceptance of corruption and the lack of accountability}

Another factor that explains health worker performance is the gradual erosion of professional norms in the health sector. This trend has direct implications for performance, but also contributes to a vicious cycle in the sector. Attitudes towards corruption are a telling indicator of how norms are changing. Both health workers and users claim that corruption is a large and a growing problem in the health sector.

Corruption came and spread widely in the last 10 years. Now corruption is prevalent among people at all levels of education and in all areas.

Physician/health officer in a provincial town

It is increasingly seen as an inescapable feature of the health sector. Although health workers are clear on the fact that stealing and overcharging are illegal and unethical, the behavior is rationalized as a result of low pay, and justified because it also happens in other sectors.

\footnotetext{
Low paid staff may be involved in small bribes of 5 or 10 Birr for access to the admissions office. The staff may claim they need help for a relation. There is some humanity and assisting this is okay because people working in other service institutions such as Ethiopian Light and Power Authority, Water Supply, etc. have the benefit of charging users for free services.
}

Physician/health officer in Addis Ababa

\footnotetext{
${ }^{9}$ Discussion participants argue for example that it is quite easy to get a full time job in the private sector without release papers, as the Ministry of Health does not effectively enforce regulations when inspecting private facilities. In other cases, workers in the private sector are not formally registered. One of the focus group participants noted that when Ministry of Health inspectors come, they simply take off their gown and pretend to be patients.
} 
Although serious cases of corruption are condemned, participants remark that there is a tradition of keeping quiet, among others because there is no direct benefit for an individual to complain.

\begin{abstract}
We health workers, and patients, have not wanted to expose corruption. It is considered indecent and we believe that it will affect our relationship. Most of us keep quiet.
\end{abstract}

Nurse/midwife in a provincial town

\begin{abstract}
We have contributed to this problem by not exposing corruption. The Ministry of Health can clean the private facilities from corruption and take corrective measures in the public sector. If the Ministry of Health is weak, all will be weak.
\end{abstract}

User in a provincial town

There are many factors that explain the acceptance of corrupt practices, but the discussion participants particularly emphasize the lack of accountability. Formal accountability arrangements are weak in both the public and private sectors, and as a consequence the system relies heavily on trust and self-regulation. ${ }^{10}$ In part, this is due to the limited capacity of the Ministry of Health, in particular at regional and district level, but officials also lack the incentives to hold providers and health workers accountable. Bottom up accountability mechanisms are also weak. In principle, problems with the local health care provider can be reported to the Kebele, the lowest level of administration, and then be brought to the attention of the Wereda. But this system does not seem to work in practice. As a result, users express frustration about not having a place where they can complain and about the lack of legal routes.

If a person dies today because of mal-practice, no health worker is going to be held responsible.

User in a provincial town

Apart from discussing with people around you, where can you go to express your complaints? If you go to the provider, the staff and managers will not disclose these issues formally because they do not want to be held responsible. The leaders and members of the Iddir and Kebele are like me and don't know where to report to. The Ministry of Health is the same as the providers. They have never taken any measure, even if there are a lot of catastrophic mistakes. There has to be a place to complain.

User in a provincial town

Health workers acknowledge that accountability is very weak, especially in the public sector. Recently, a new system of performance management has been introduced in the public sector. ${ }^{11}$ However, the system is still in its infancy, its operation remains unclear, and some express concern about its lack of objectivity and transparency. In practice, promotion remains based on time served and personal connections, and disciplinary measures remain virtually

${ }^{10}$ For example, the media is only starting to play the role of a watchdog, and this is limited to Addis Ababa.

${ }^{11}$ Under this system, promotions, training opportunities, and salary increments will be tied to health worker performance. 
unheard of. The new system also does not make health workers accountable to the users of health services. Again, the on going decentralization may offer new opportunities to strengthen both top-down and bottom- up accountability. ${ }^{12}$

\subsection{The impact of HIV/AIDS}

In 2000 there were an estimated 2.6 million people living with HIV/AIDS in the Ethiopia (Ministry of Health, 2000), corresponding to a prevalence rate of 6.6 percent (World Bank \& Ministry of Health (Ethiopia), 2004). Awareness about HIV/AIDS is high (Central Statistical Authoririty \& ORC Macro, 2001) and this may explain its profound impact on the health profession. At the most immediate level, the HIV/AIDS crisis has affected the nature and volume of health work and has put a strain on both human and material resources.

HIV/AIDS has affected the management and handling of patients. Because the disease affects the immune system, infected patients come more frequently. This affects the management, behaviour and morale of the physician. Because there are so many patients infected, it requires large resources in material and manpower, which the country lacks.

Physician/health officer in a provincial town

But the high workload, the lack of protective material, and poor safety procedures have also exposed health workers to new risks. The discussion participants are acutely aware of these risks, and they admit that it affects their behavior in the workplace.

The effect of HIV/AIDS on health workers has been totally ignored. It is difficult to differentiate between patients who are infected with the virus and those who are not. Handling patients is difficult because of the low level of understanding of issues involved. In the face of extreme shortages of gloves and other supplies, we are exposed to difficult situations; it is like sacrificing your life. This is especially the case at lower levels and in rural areas.

Health assistant in a provincial town

One is not secure against contracting the virus during treatment. The present procedure for post exposure to HIVIAIDS is to take prophylaxis treatment if tested positive, and one has to take post-exposure prophylaxis for 4 weeks. But this is only what it says on paper. It is not practiced. Nobody is really working toward protecting health professionals.

Physician/health officer in a provincial town

There is no health insurance. For example, if staff contracts HIV/AIDS while treating patients, he or she does not receive any care or support from the facility. The infected person just dies.

Health assistant in Addis Ababa

\footnotetext{
12 A community interviewed during the pilot, told us that in the same week that they obtained the authority to manage their health post, they knocked down the building and turned the site into agricultural land, since that was 'more productive'. In other cases, accountability arrangements have been more formalized. A Woreda in Tigray requires all facilities to report staff evaluations every six months. If not submitted to the Woreda in time, the facility drops in ranking, with implications for future financing.
} 
I had the following experience. There was a pregnant lady who went for treatment. All the health workers were afraid to touch the woman and it was us who were helping her to move around. There is great fear and health workers are not willing to touch the clothes of some patients, let alone their body, even if wearing gloves; they do not trust the gloves.

User in Addis Ababa

The concerns of health workers about HIV/AIDS risks are important in their own right, but they also have implications for the labor market. Health workers speak of a growing desire to steer their career away from clinical activities towards public health or administration. Some say that their move to the private sector is motivated by a concern with HIV/AIDS, as lower patient turn-over and better protective material and procedures lead to a lower risk of infection. New candidates may ultimately choose to stay away from the profession to avoid the risk of contracting HIV/AIDS.

Many health workers who originally wanted to do clinical work now choose public health. Surgical training is more risky, while preventive care is seen as a relatively safer area.

Physician/health officer in Addis Ababa

I have a son who used to be very interested in joining the medical profession. Last year he got straight A's in school but preferred to join another profession. His reason was that he had observed the risk his parents are exposed to-we are both working in the health sector... Everyday my 9 year old daughter asks me how I spent my day. She asks me 'did you have any patient that bled? If so, please wash your hands with hot water and change your clothes.'

Health assistant in a provincial town

\section{SUMMARY AND CONCLUSION}

This paper reports findings fom focus group discussions with health workers and users of health services in Ethiopia. The aim of the discussions is to generate insights into the nature and sources of performance problems of health workers, and the perspectives of health workers on career and labor market issues. In the first part of the paper we describe performance problems identified by both health users and health workers participating in the discussions. In the second part we present four structural reasons why performance problems arise, and how they relate to human resource policies.

The group discussions identify a number of problems, including absenteeism and shirking, pilfering drugs and materials, informal health care provision, illicit charging, and corruption. These problems have been documented in other studies from Ethiopia and elsewhere. However, in contrast to much previous work, the focus group discussions provide detailed insight into why the problems arise. The participants make clear that the problems are rooted in the ongoing transition from a command-and-control health sector, to a more pluralistic system. In this transition, human resource policies have not kept up with new realities. An inadequate policy and regulatory framework, combined with weak enforcement, has created new opportunities and altered incentives, while at the same time contributing to an erosion of trust and professional norms among health workers. On top of these health system 
changes, the HIV/AIDS crisis has brought new challenges for a profession that was already trying to cope in a difficult environment.

In this context, health workers have responded strategically and purposively. Many prefer to hold a portfolio of jobs-combining public and private sector work-to cope with or manage career risks. Eager to make use of new opportunities in urban areas, health workers are reluctant to accept rural postings, and many find ways of avoiding rural assignment. The availability of new opportunities, especially in the private sector, in combination with weak accountability mechanisms and eroded commitment, has resulted to the documented performance problems in public facilities, as well as growing problems of corruption in the sector as a whole.

Although our findings should not be seen as representative in a quantitative sense, they raise important issues. Under the current conditions, the health system risks becoming segmented, with the better off benefiting from high quality care provided in the private sector, while the majority, including the poor, only have access to low quality public health care. In the absence of an effective policy response, HIV/AIDS and other factors are likely to speed up the outflow of health workers from the sector, while possibly also reducing the inflow of new workers; while rural-urban imbalances will persist or worsen.

Overall, the discussions with both health workers and users illustrate the need for effective human resource policies and management in a country like Ethiopia. Both policies and the way they are implemented need to be revised and strengthened on the basis of an understanding of how health workers make constrained choices, both in their career and in their day to day professional activities. In doing so, crucial ingredients such as accountability mechanisms, links between the public and private sectors, and an effective response to HIV/AIDS risks in the workplace need to be considered. Only a thorough revision of existing human resource policies can help to build a health system that is able to tackle the health problems of the poor. Many health workers remain committed, but they are waiting for urgent change.

Even though there are many problems, I would advise even my children to join the health profession. Tomorrow is another day and things may change. Any profession has its own unique hazards and problems. The most important things in Ethiopia are education and health, and the need in these sectors is great.

Physician/health officer in Addis Ababa

\section{APPENDIX}

\subsection{Details on methodology and data collection}

By design, focus group discussions are neither objective nor representative. Yet, the approach has many advantages (Yach 1992). Focus group discussions permit researchers to elicit a multitude of views that cannot be obtained as easily through individual interviews, and 
the participative nature of the discussion permits the researcher to explore and contrast the views of different participants. Well managed focus group discussions can also be powerful to exploring sensitive issues (Farquhar, 1999) such as corruption. However, the findings from these discussions are sensitive to the methodology that is applied. This section provides a detailed description of (i) the focus group organization, composition, and implementation; and (ii) the transcription and analysis.

\section{Focus group organization, composition, and implementation}

A total of nine focus group discussions were carried out. Five of them were implemented in the capital, four in a provincial town. In each of the two locations, we held separate group discussions with (i) medical doctors and health officers; (ii) nurses and midwifes; (iii) health assistants; and, (iv) users of health services (see Table 1)

Table 1: Type of Focus Group Discussions

\begin{tabular}{lcc}
\hline Focus groups & $\begin{array}{c}\text { Addis } \\
\text { Abeba }\end{array}$ & $\begin{array}{c}\text { Provincial } \\
\text { town }\end{array}$ \\
\hline Health users & 2 & 1 \\
Doctors, specialists and health officers & 1 & 1 \\
Nurses and mid wives & 1 & 1 \\
Health assistants & 1 & 1 \\
\hline
\end{tabular}

The composition of the groups was based on three criteria (i) promotion of group dynamics; (ii) within-group status homogeneity; and (iii) within-group heterogeneity along dimensions that affect career concerns and performance. To promote constructive group dynamics, we ensured that the participants did not know either each other or the discussion leader in advance, and that they were willing to actively participate in the group discussion. Within-group status homogeneity was achieved by separating occupations that have a different social status (e.g. physicians and nurses), thereby creating conditions for open discussion. To obtain within-group heterogeneity along dimensions of interest, we used the following criteria for the recruitment of participants. For the groups of health workers, we selected participants based on (i) their occupation; (ii) their gender; (iii) whether they have children; (iv) sector of employment; and (v) whether they combine public and private sector work. For the users we applied the following criteria: (i) having visited a health facility during the last year; (ii) not being a health worker or a relative of a health worker; (iii) sex; (iv) family situation; (v) the type of facility they use most frequently (private, public or not for profit); and (vi) whether they have experience with in-patient treatment. In Addis Ababa, an income criteria was also used. In the first group all participants earned more than 500 Birr (60 USD) per month, all of them primarily use private health care now, but had used public health care in the past. In the second group all participants earned below 500 Birr; they use public health care, and some of them have tried private health care. During the recruitment, the participants are informed that they would be reimbursed for their transport and time. In the capital all health workers were paid 100 Birr (13 USD) each, the health users were paid 50 Birr (7 
USD) each. In the provincial town, all participants were paid 50 Birr (7USD). The composition of the focus group s is described in Table 2.

Table 2: Focus group composition

\begin{tabular}{|c|c|c|c|c|}
\hline Composition of focus groups & $\begin{array}{l}\text { Addis } \\
\text { Abeba }\end{array}$ & $\begin{array}{c}\text { Provincial } \\
\text { town }\end{array}$ & Total & $\%$ of Total \\
\hline Health workers & 23 & 24 & 47 & $100.0 \%$ \\
\hline $\begin{array}{l}\text { of which } \\
\text { Health assistants } \\
\text { Nurses \& midwifes } \\
\text { Doctors \& health officers }\end{array}$ & $\begin{array}{l}8 \\
7 \\
8\end{array}$ & $\begin{array}{l}8 \\
8 \\
8\end{array}$ & $\begin{array}{l}16 \\
15 \\
16\end{array}$ & $\begin{array}{l}34.0 \% \\
31.9 \% \\
34.0 \%\end{array}$ \\
\hline $\begin{array}{l}\text { Female } \\
\text { Male }\end{array}$ & $\begin{array}{l}12 \\
11\end{array}$ & $\begin{array}{l}11 \\
13\end{array}$ & $\begin{array}{l}23 \\
24\end{array}$ & $\begin{array}{l}48.9 \% \\
51.1 \%\end{array}$ \\
\hline $\begin{array}{l}\text { With children } \\
\text { No children }\end{array}$ & $\begin{array}{l}17 \\
6\end{array}$ & $\begin{array}{l}18 \\
6\end{array}$ & $\begin{array}{l}35 \\
12\end{array}$ & $\begin{array}{l}74.5 \% \\
25.5 \%\end{array}$ \\
\hline $\begin{array}{l}\text { Public } \\
\text { Private for-profit } \\
\text { NGO }\end{array}$ & $\begin{array}{l}11 \\
4 \\
8\end{array}$ & $\begin{array}{l}10 \\
7 \\
7\end{array}$ & $\begin{array}{l}21 \\
11 \\
15\end{array}$ & $\begin{array}{l}44.7 \% \\
23.4 \% \\
31.9 \%\end{array}$ \\
\hline $\begin{array}{l}\text { Users } \\
\text { of which }\end{array}$ & 14 & 8 & 22 & $100.0 \%$ \\
\hline $\begin{array}{l}\text { Female } \\
\text { Male }\end{array}$ & $\begin{array}{l}6 \\
8\end{array}$ & $\begin{array}{l}2 \\
6\end{array}$ & $\begin{array}{c}8 \\
14\end{array}$ & $\begin{array}{l}36.4 \% \\
63.6 \%\end{array}$ \\
\hline $\begin{array}{l}\text { With chidren } \\
\text { No children }\end{array}$ & $\begin{array}{l}11 \\
3 \\
\end{array}$ & $\begin{array}{l}5 \\
3 \\
\end{array}$ & $\begin{array}{l}16 \\
6 \\
\end{array}$ & $\begin{array}{l}72.7 \% \\
27.3 \% \\
\end{array}$ \\
\hline
\end{tabular}

The discussions were semi-structured, following a prepared interview guide which serves as a check-list for the topics discussed and were held at a meeting room in a hotel to avoid distraction. When all participants had arrived, they were asked to take a place around a table. In the introduction, given by the authors, the participants were informed about the purpose of the discussion, the importance of open and honest participation, and the full confidentiality of any information disclosed during the discussions.

The discussions were held in English for the doctors, specialists and health officers, and in Amharic for the nurses and midwifes, health assistants, and the health users. Each session lasted approximately two hours and was audio recorded. At the end of the discussion, each participant was asked to fill out a short questionnaire.

\section{Focus group transcription and analysis}

All focus group discussions were transcribed in English, providing a full record of each of the discussions. Because the discussions were not recorded on video, it was impossible to systematically relate opinions to specific participants. Through the process of analysis, the discussion transcripts were synthesized and contextualized. This was done by identifying key themes in the transcripts, focusing on issues that were mentioned frequently or consistently, that received particular emphasis, or for which views expressed in the interviews diverged in systematic ways. The textual data was structured in matrices, with different columns for each 
type of group, and rows for different thematic areas. This approach facilitates comparison across as well as within groups, while avoiding excessive structure.

\section{REFERENCES}

Belli, P., Gotsadze, G., \& Shahriari, H. (2004). Out-of-pocket and informal payments in health sector: evidence from Georgia. Health Policy, 70(1), 109-123.

Central Statistical Authoririty, \& ORC Macro (2001). Ethiopia Demographic and Health Survey 2000.

Chaudhury, N., Hammer, J.S., Kremer, M., Muralidharan, K., \& Rogers, H. (2004). Teacher and Health Care Provider Absence: A Multi-Country Study: World Bank. Mimeo.

Dussault, G., \& Dubois, C.-A. (2003). Human resources for health policies: a critical component in health policies. Human Resources for Health, 1(1).

Ensor, T., \& Witter, S. (2001). Health economics in low income countries: adapting to the reality of the unofficial economy. Health Policy, 57(1), 1-13.

Ensor, T. (2004). Informal payments for health care in transition economies. Soc Sci Med, 58(2), 237-246.

Farquhar, C. (1999). Are focus groups suitable for 'sensitive' topics? In R. Barbour, \& J. Kitzinger (Eds.), Developing focus group research: politics, theory and practice. London: Sage.

Ferrinho, P., Van Lerberghe, W., Julien, M.R., Fresta, E., Gomes, A., Dias, F., Goncalves, A., \& Backstrom, B. (1998). How and why public sector doctors engage in private practice in Portuguese-speaking African countries. Health Policy Plan, 13(3), 332338.

Ferrinho, P., \& Van Lerberghe, W. (2002). Managing Health Professionals in the Context of Limited Resource: a Fine Line Between Corruption and the Need for Moonlighting. Unpublished manuscript.

Ferrinho, P., Omar, M.C., Fernandes, M.D., Blaise, P., Bugalho, A.M., \& Lerberghe, W.V. (2004). Pilfering for survival: how health workers use access to drugs as a coping strategy. Hum Resour Health, 2(1), 4.

Franco, L.M., Bennett, S., \& Kanfer, R. (2002). Health sector reform and public sector health worker motivation: a conceptual framework. Social Science and Medicine, $54,1255-1266$.

ILO (1998). Terms of employment and working conditions in health sector reforms. Geneva: International Labour Office.

Joint Learning Initiative (2004). Human Resources for Health: Overcoming the Crisis.

Martinez, J., \& Martineau, T. (1998). Rethinking human resources: an agenda for the millennium. Health Policy Plan, 13(4), 345-358.

McPake, B., Asiimwe, A., Mwesigye, F., Ofumbi, M., Orthenblad, L., Streefland, P., \& Turinde, A. (1999). Informal economic activities of public health workers in Uganda: implications for quality and accessibility of care. Social Science and Medicine, 49(4), 849-865.

Ministry of Health (1999). Qualifications of Requirements for Health Professionals: Ministry of Health, Government of Ethiopia.

Ministry of Health (2000). Aids in Ethiopia: mimeo. 
Ministry of Health (2003). Guidelines on Management and Operations of Private Wings in Public Hospitals: mimeo.

PAHO (2001). Development and Strengthening of Human Resources Management in the Health Services: Pan American Health Organization and World Health Organization. Processed.

UNICEF (2003). http://www.childinfo.org/: UNICEF.

USAID (2003). The Health Sector Human Resource Crisis in Africa: An Issues Paper. Washington, DC.: USAID.

Van Lerberghe, W., Adams, O., \& Ferrinho, P. (2002). Human resources impact assessment. Bull World Health Organ, 80(7), 525.

Walelign, N., \& Yusuf, Y. (2002). Special Pharmacies in Ethiopia: opportunities, challenges, and the way forward: mimeo.

WHO (2002). Human resources and national health systems: shaping the agenda for action: WHO/EIP.OSD/03.2.

World Bank, \& Ministry of Health (Ethiopia) (2004). Ethiopia: A Country Status Report on Health and Poverty.

Yach, D. (1992). The Use and Value of Qualitative Methods in Health Research in Developing Countries. Social Science and Medicine, 35(4). 